\title{
Predictors of Payer Mix and Financial Performance Among Safety Net Hospitals Prior to the Affordable Care Act.
}

\section{Citation}

Sommers, Benjamin D., Julia Stone, Nancy Kane. 2016. Predictors of Payer Mix and Financial Performance Among Safety Net Hospitals Prior to the Affordable Care Act. Internatonal Journal of Health Services 46 (1):166-184.

\section{Published Version}

10.1177/0020731415586408

\section{Permanent link}

http://nrs.harvard.edu/urn-3:HUL.InstRepos:14302699

\section{Terms of Use}

This article was downloaded from Harvard University's DASH repository, and is made available under the terms and conditions applicable to Open Access Policy Articles, as set forth at http:// nrs.harvard.edu/urn-3:HUL.InstRepos:dash.current.terms-of-use\#OAP

\section{Share Your Story}

The Harvard community has made this article openly available.

Please share how this access benefits you. Submit a story.

\section{Accessibility}




\section{Predictors of Payer Mix and Financial Performance Among Safety Net Hospitals Prior to the Affordable Care Act}

Authors: Benjamin D. Sommers, Juliana Stone, and Nancy Kane

\section{Corresponding Author:}

Benjamin D. Sommers, MD, PhD

Assistant Professor of Health Policy \& Economics

Harvard T. H. Chan School of Public Health / Brigham \& Women's Hospital 677 Huntington Ave, Kresge Room 406

Boston, MA 02115

(617) 432-3271

bsommers@hsph.harvard.edu 


\section{ABSTRACT}

Objective: To use audited hospital financial statements to identify predictors of payer mix and financial performance in safety net hospitals prior to the Affordable Care Act. Data Sources/Setting: We analyzed the 2010 financial statements of 98 large urban safety net hospital systems in 34 states, supplemented with data on population demographics, hospital features, and state policies.

Study Design: We used multivariate regression to identify independent predictors of three outcomes: 1) Medicaid-reliant payer mix (hospitals for which at least 25\% of hospitals days are paid for by Medicaid); 2) Safety net revenue-to-cost ratio (Medicaid and Medicare Disproportionate Share Hospital payments and local government transfers, divided by charity care costs and Medicaid payment shortfall); and 3) Operating margin. Principal Findings: Medicaid-reliant payer mix was positively associated with more inclusive state Medicaid eligibility criteria and more minority patients. More inclusive Medicaid eligibility and higher Medicaid reimbursement rates positively predicted safety net revenue-to-cost ratio. University governance was the strongest positive predictor of operating margin.

Conclusions: Safety net hospital financial performance varied considerably. Academic hospitals had higher operating margins, while more generous Medicaid eligibility and reimbursement policies improved hospitals' ability to recoup costs. Institutional and state policies may outweigh patient demographics in the financial health of safety net hospitals.

Key Words: Hospitals, Medicaid, health reform 


\section{INTRODUCTION}

Safety net hospitals that disproportionately care for low-income populations, often free of charge, face major financial changes in the coming decade due to the Affordable Care Act (ACA). Because safety net institutions predominantly see low-income populations covered by Medicaid or with no coverage at all, costs can be high and revenue inadequate. For example, in 2010, an analysis of hospital survey data revealed that the average financial margin for safety net hospitals was reportedly 2.3 percent, compared to a 7.2 percent for all U.S. hospitals.[1] The 1981 Omnibus Budget Reconciliation Act (OBRA) recognized the high financial burden incurred by hospitals that serve uninsured patients and low-income patients with special needs.[2] Over the following years, what became known as the Medicaid and Medicare Disproportionate Share Hospital (DSH) program provided additional payments to these facilities beyond the normal insurance reimbursement from Medicare and Medicaid. Combined with local and state government subsidies from sales and property taxes, DSH payments were intended to provide at least partial reimbursement for otherwise uncompensated care.

The ACA, which was passed into law in March 2010, brings many key changes to the financial circumstances of these hospitals. On the one hand, most hospitals will likely experience increases in the number of patients with insurance, since one of the law's chief aims was expanding coverage to Americans without health insurance. To accomplish this aim, the ACA included a provision to expand Medicaid eligibility to adults with incomes at or below $138 \%$ of the federal poverty level (FPL) beginning in 2014 , corresponding to roughly $\$ 16,000$ in annual income for an individual or $\$ 33,000$ 
for a family of four. Additionally, the law made tax credits available to those with incomes up to $400 \%$ of the FPL to subsidize premiums for private health insurance. These two policies have already been linked to an additional 10 million adults gaining health insurance in 2014, thus bringing in needed revenue to safety net hospitals.[3]

On the other hand, several sources of safety net funding will decline over the coming decade. Due to predicted coverage increases, the ACA includes a provision to cut Medicare DSH funding by $75 \%$ and Medicaid DSH funding by up to $50 \%$.[4] These cuts will occur gradually; for instance, the Medicaid DSH cuts were originally slated to start at 4\% in 2014 and increase to $49 \%$ in 2020,[4] though recent negotiations have delayed the onset until 2016.[5] Cuts will vary by state, based on the percentage of uninsured in the state and the state's allocation of DSH payments to hospitals that provide more care to Medicaid and uninsured patients. In an attempt to incentivize states to target their DSH funds to the hospitals in greatest need, the biggest DSH cuts will be experienced by states that provide their DSH funding to hospitals regardless of how much uncompensated care they provide.[2]

Continued financial viability in the face of such funding cuts presupposes an expansion of Medicaid coverage that can make up the difference. However, in 2012, the Supreme Court effectively ruled that the Medicaid expansion was optional. States could choose to opt-out of expanding eligibility requirements and continue to using their own pre-ACA eligibility cutoffs that were typically much more restrictive. More than 20 states have decided not to expand Medicaid as of October 2014, leaving over 6 million people uninsured and without an option for affordable coverage.[6] Meanwhile, DSH cuts apply 
to all states, whether they decide to expand Medicaid or not.[7] Furthermore, undocumented immigrants and low-income legal immigrants who have been in the U.S. for less than five years will likely remain uninsured, as the ACA does not grant eligibility for Medicaid coverage to this population. Finally, the perception that the ACA will grant near universal coverage may prompt state or local-level allocation of tax dollars elsewhere, leaving safety net hospitals even more financially vulnerable.

Despite significant policy activity and interest in these issues, the evidence base on the financial performance of safety net hospitals is quite sparse, in large part due to data limitations. Some information on financial performance is available from surveys of hospitals,[8] though the accuracy and uniformity of responses in self-reported data has not been independently confirmed. Others have relied on financial data reported in the Medicare Cost Report - expense reports that must be filed on a yearly basis by all facilities receiving Medicare reimbursements. However, these reports do not disclose important details such as the cost of free care or Medicaid DSH payments. The quality of data in these reports has also been shown to be highly variable, with important factual inconsistencies when compared to hospital financial statements produced by independent auditors as required by outside creditors.[9] Furthermore, financial information from surveys and the Medicare Cost Report generally report on the hospital entity alone and therefore do not reflect the financial condition of the entire organizational entity within which the hospital is owned and operated. Yet most hospitals are in multi-entity systems that often include other hospitals, physician practices, health plans, and other operating entities that can have a material financial impact on the hospital entity. 
An alternative approach that overcomes many of these limitations is using audited hospital financial statements, which, as discussed below, are subject to several quality controls and independent validation, unlike survey data or the Schedule G (income statement and balance sheet items) of the Medicare Cost Reports. A recent study by Kane et al. examined the financial performance of large urban publicly-owned safety net health systems using audited financial statements, which demonstrated the feasibility of using this data source for research purposes. Kane et al. found that the sample of safety net systems earned positive operating margins (median of $1.7 \%$ in 2010) but hospitals in the sample had considerable variation in financial performance, which was highly contingent on DSH funding and local government tax dollars.[10]

It remains unclear what factors are most closely linked to financial distress among safety net hospitals and health systems. Qualitative analyses and case studies have linked better performance among some hospitals to elements of successful strategic management,[11] while others have conceptualized safety net hospitals as operating within a medical arms race, with viability predicated on the adoption of private sector strategies to expand, to renovate, and to attract more generous payers.[12] Often, patient demographic characteristics are assumed to be a key factor in determining the financial wellbeing of safety net hospitals. For instance, Mohan et al. examined the impact of the 2006 health care reform in Massachusetts on volume, revenue, and operating margins, concluding that despite increases in coverage, safety net hospitals continued to care predominately for disadvantaged populations while experiencing poorer financial performance after the reform than other hospitals.[13] However, we are unaware of any 
broader national analyses of demographic predictors of financial performance.

Furthermore, quantitative evidence on the financial impact of state policies and hospital features is lacking.

The objective of this study was to characterize several key features of financial performance in a sample of public and private safety net hospitals from across the United States, using 2010 audited financial statements. Merging this information with state policy variables from several published sources and local demographic features from Census data, we examine potential risk factors for poor health system financial performance. Our goal was to assess the relative contributions of patient demographics, hospital system features, and state policies to the financial health of safety net hospitals on the eve of the ACA's implementation.

\section{METHODS}

\section{Overview of Analytical Approach}

Using audited financial statements from 2010 and other hospital-reported information, we identified three outcome variables related to financial performance, as defined in the next section. We then collected information on hospital features, demographics of the population living in the area around each hospital, and key state policies related to safety net hospital financing. Our analytical model used multivariate regression to identify which of these institutional, demographic, and policy factors were independent predictors of safety net hospital financial performance. 


\section{Data and Variables}

Hospital Audited Financial Statements and Hospital Characteristics

Our source of financial data was the audited financial statements of the medical systems that contained our sample of safety net hospitals. Audited financial statements, considered the "gold standard" of financial reporting, are required to present a balance sheet, a statement of operations ("income statement"), a statement of changes in net assets (changes in net worth), and a statement of cash flow, as well as provide detailed footnotes disclosing accounting policies and important details such as the amount of free care provided, the amount of Medicaid supplemental payments realized, local government financial support, and other financially material considerations. The financial statements are audited by independent outside auditors, and in order to obtain debt financing, management must attest to the accuracy and fair representation of the financial information.

The Securities and Exchange Commission (SEC) now requires public disclosure of audited financial statements of all health systems issuing tax-exempt debt in a single municipal repository.[14] This recent requirement, enacted in 2009, has generated a record number of public and private non-profit health system filings, as intended. It thus created an unprecedented opportunity to capture the financial health of safety-net hospital systems.

In addition to audited financial statements, we also obtained various hospitalrelated measures such as Medicaid inpatient utilization rates from the American Hospital Directory (AHD), a commercial database derived from the Medicare Cost Report.[15] 
For multihospital systems these hospital measures were aggregated to the level of the system.

We identified three distinct outcomes of payer-mix and financial performance in these safety net hospitals, which move from the most specific to the broadest:

1. Medicaid-Reliant Hospitals: From AHD data, we assessed which hospital systems were "Medicaid-reliant hospitals," defined as those with at least $25 \%$ of their hospital days coming from Medicaid patients (this represented approximately the top one-third of the sample on this measure).

2. "Safety Net Ratio": From financial statements and federal DSH data,[16] we constructed a safety net revenue-to-cost ratio, which was defined as the sum of Medicaid and Medicare DSH payments and local government transfers, divided by the total costs of charity care plus Medicaid payment shortfall. Cost of charity care was derived based on dividing the total amount of free care (valued at charges) by the hospital's markup of charges over total operating cost. 3. Operating Margin: From audited financial statements, we measured the overall operating margin for each hospital system (total operating revenue minus total operating expense, divided by total operating revenue).

For potential institutional-level predictors of financial performance, we identified the following hospital-system level features from the AHD database: 1) Ownership status (non-profit; owned by the hospital District, a government-sponsored entity designed solely to operate the hospital system; or publicly owned by a government other than the 
District - typically a state, county or municipality); 2) Governance, based on the dominant model used for each hospital system (university-run; run by a publicly-elected board of directors; run by individuals appointed by elected government officials; or run by a self-nominating private board); and 3) Census region (Northeast, Midwest, South, and West).

\section{Demographic Characteristics of Hospital Areas}

To measure the demographic features of the population living around each hospital, we used the Census Bureau's 2010 American Community Survey (ACS). The ACS is the government's largest survey, with approximately 3 million observations each year in the publicly-available dataset. Geography in the ACS public use file is coded into Public-Use Microdata Areas (PUMAs). PUMAs represent areas within a given state that have a population of at least 100,000 individuals. PUMAs in low-population density areas may contain multiple counties, or alternatively may comprise much smaller areas within a single more densely populated county. Since nearly all of our hospitals are located in well-populated urban areas, in practice most of the PUMAs in our sample were portions of metropolitan areas significantly smaller than a county. For instance, Los Angeles county is divided into 35 PUMAs. While hospitals may draw patients from areas larger or smaller than PUMAs depending on the circumstance, a population base of roughly 100,000 is more than adequate to capture the key demographic features of a hospital's surroundings while still providing a narrower definition than would be possible using statewide or county-wide measures. 
For each hospital, we identified the PUMA containing that hospital using coordinates for each hospital's address mapped against Census PUMA information; geocoding was double-checked by two independent investigators. Next, we assigned each hospital system the survey-weighted percentages of the following three demographic features for all individuals living in the PUMA: 1) percentage of non-citizens, 2) percentage of racial/ethnic minorities (defined as non-whites and/or Latinos), and 3) percentage with incomes below the Census federal poverty threshold. When hospital systems contained multiple hospital locations, we used the weighted average for these statistics, based on the total revenue for each component hospital.

\section{Medicaid Policy Features}

We identified measures of several aspects of state policy with major potential implications for safety net hospitals, in the areas of Medicaid and DSH:

1) Medicaid eligibility, which captured the percentage of a standardized population of adults eligible for Medicaid based on each state's 2010 pre-ACA criteria, as used in previous research[17] and detailed elsewhere.[18] Before the ACA, each state had broad discretion to set its income thresholds that granted an individual or family eligibility for Medicaid coverage. The dramatic variability in eligibility thresholds preACA can be demonstrated by comparing New York and Texas, as of 2009. In New York, any adults with incomes below $100 \%$ of FPL and parents with incomes below $150 \%$ of FPL were eligible for Medicaid. In contrast, in Texas, parents were only eligible up to 
$26 \%$ of FPL, and adults without children and without a disability were not eligible, no matter how poor they were.[19]

2) Medicaid hospital payment rates, measured by the hospital's Medicaid payment-to-cost ratio, as reported in financial statements.

3) States with low levels of Medicaid DSH allotments from the federal government, as defined by recent federal guidance from the Department of Health and Human Services.[2]

4) The degree to which each state targeted its DSH funding to safety net providers, also based on HHS regulatory guidance from 2013. This latter measure was based on HHS' proposed methodology for reducing state DSH allotments in 2014 in those states that poorly target DSH funds to the hospitals that mainly provide care to Medicaid and uninsured patients. We defined this measure as the ratio of HHS's proposed DSH reduction in each state due to poor targeting, compared to its baseline DSH allotment, with the scale inverted (-100\% to $0 \%)$ so that higher numbers indicated better targeting of DSH funds within the state.

\section{Sample Selection}

Our target sample for inclusion in the study consisted of large public or non-profit urban safety net hospitals. We identified potential hospital systems for the sample based on hospital ownership, urban location, and bed size greater than 150 using the AHD database. We initially identified 159 large urban publicly-owned hospitals in 30 states, for which we were able to locate 2010 audited financial statements for 95 hospitals in 83 
systems. To expand the regional representation of the sample, we added 15 large private nonprofit systems with high Medicaid utilization and uncompensated care, five of which were conversions of public hospitals. This brought our sample to 110 safety net hospitals in 98 systems. The 98 systems also included another 73 hospitals that were not large urban safety net hospitals, but their financial data was consolidated at the system level.

This yielded a sample size of 98 hospital systems across 34 states for our primary analyses. Analyses of the safety net revenue-to-cost ratio were limited to the 62 hospital systems that reported Medicaid DSH amounts in their financial statements.

\section{Statistical Analysis}

For each of our three outcomes, we conducted both univariate and multivariate analyses using linear regression models. Univariate analyses considered each set of predictor variables in isolation: hospital ownership, hospital governance, percentage minorities, percentage non-citizens, percentage living below poverty, Census region, Medicaid eligibility index, Medicaid payment-to-cost ratio, DSH allotment (high versus low), and state targeting of DSH allotments to safety net hospitals.

Multivariate models included all these variables simultaneously, with the exception of our analysis of state policies. Three of the state policies considered here were highly correlated with geographical region: Medicaid eligibility, DSH allotment, and DSH targeting were all highest in the Northeast, while eligibility and DSH targeting were lowest in the South. (Medicaid payment-to-cost ratios did not vary significantly by region.) Thus, to estimate the impact of these policies in the multivariate regressions, we 
excluded regional controls from those analyses, since the regional dummies absorbed most of the meaningful variation in these policies.

All analyses used linear models for ease of comparability of coefficients across the different outcomes, which all refer to percentage-point changes in the outcomes. Using logistic models for the one binary outcome (high Medicaid payer mix) yielded largely similar results, with a few differences noted below. Results in the next section focus on the multivariate-adjusted regression estimates, unless otherwise indicated, with a $\mathrm{p}$-value for significance $\mathrm{p} \leq 0.05$. All analyses used Stata 12.0.

\section{RESULTS}

Table 1 describes the study sample. In our sample of 98 hospital systems, the majority of systems were publically owned by state or local governments and presided over by a publicly-appointed governing board. 59\% were located in the South. Linkage with Census data indicates that the hospital systems were located in areas with populations that were disproportionately poor $(17 \%)$ and belonging to racial or ethnic minorities (39\%).

Figure 1 presents the distribution of safety net revenue-to-cost ratios and operating margins for our study sample. The median safety net ratio was 1.025 , indicating $\mathrm{a}+2.5 \%$ safety net margin, with an interquartile range from $-32.4 \%$ to $+32.6 \%$. The median operating margin was $+1.7 \%$, with an interquartile range from $-0.3 \%$ to $+4.5 \%$.

Table 2 displays univariate and multivariate regression results for predictors of high-Medicaid payer mix, using a linear probability model. Hospital ownership, hospital 
governance, and region had no statistically significant association with the Medicaid payer-mix outcome. As expected, the state Medicaid eligibility index strongly correlated with the likelihood of being a hospital with a high-Medicaid payer mix, in both unadjusted (coefficient $=+5.59, \mathrm{p}<0.001)$ and adjusted analyses $(+3.94, \mathrm{p}=0.013)$. Higher Medicaid payment rates - which tended to vary inversely with eligibility in our data were significantly associated with lower Medicaid payer mix $(-0.51, \mathrm{p}=0.017)$, but only in the univariate model. Demographics of the surrounding area were also a significant predictor of higher Medicaid payer mix. In univariate models, the proportion of noncitizens $(+2.29, \mathrm{p}=0.001)$ and proportion of non-whites or Latinos $(+0.67, \mathrm{p}<0.001)$ were significant positive predictors of Medicaid-reliant payer mix. After adjustment, these predictors lost statistical significance, which appears to be due to colinearity between those two measures. Repeating the multivariate model with hospital and policy features but including only one demographic variable at a time indicated that all three measures the percentage of minorities $(+0.61, \mathrm{p}=0.002)$, of non-citizens $(+1.87 \mathrm{p}=0.018)$, and those below the poverty line $(+1.22, \mathrm{p}=0.056)-$ were reasonably strong positive predictors of Medicaid payer-mix.

Univariate results for payer-mix were identical when using logistic models instead of linear models. The logistic multivariate model showed the same impact of Medicaid policies and demographics, but also indicated publicly-owned hospitals and those with an elected board of directors were more likely to be Medicaid-reliant.

Table 3 displays univariate and multivariate regression results for predictors of the safety net revenue-to-cost ratio, which measures hospitals' ability to recoup costs for 
care provided to low-income patients. Overall, the strongest predictors in adjusted models were the Medicaid eligibility index $(+8.66, \mathrm{p}=0.008)$ and the Medicaid payment-to-cost ratio $(+1.36, \mathrm{p}<0.001)$. Non-profit status was a significant negative predictor of the safety net ratio but only in the adjusted model. Hospital ownership, hospital governance, hospital area demographics, region, and DSH-related state policies showed no significant association with the safety net revenue-to-cost ratio. For this outcome, roughly a third of hospital systems did not list any DSH allotments in their financial reports, and we excluded them from our primary analysis. It is unclear whether such hospitals simply did not receive any DSH payments, or received them but chose not to report them. In a sensitivity analysis in which we included these hospital systems and treated them as having \$0 in DSH allotments, the results were quite similar as those in Table 3.

Table 4 displays results for predictors of hospital system operating margin. University governance $(+0.04, \mathrm{p}=0.030)$ was a positive predictor of operating margin, while location in the Northeast $(-0.06, \mathrm{p}=0.016)$ was a negative predictor, and these relationships were similar in both adjusted and unadjusted models. Hospital ownership, hospital area demographics, and state policies showed no significant association with operating margin in either univariate or multivariate models.

\section{DISCUSSION}

Financial circumstances of safety net hospitals will change significantly as a consequence of the ACA. Understanding the factors driving these hospitals' financial performance prior to the ACA is critical for guiding policy in this area. Our paper 
contributes to an ongoing effort to strengthen what has been a research literature plagued by sparse evidence and non-validated data sources. Using audited financial statements and focusing on the broader health systems within which safety net hospitals operate, we present suggestive findings on the underlying risk factors for poor financial performance in large urban safety net hospitals.

In assessing the predictors of financial performance, our findings suggest that one piece of conventional wisdom - that patient demographics determine a hospital's financial destiny[20] - may not hold. Being located in an area with high shares of minorities, low-income individuals, and non-citizens was significantly associated with a high Medicaid payer mix, as was the generosity of each state's pre-ACA Medicaid eligibility criteria. However, patient demographics did not significantly predict either of our financial performance measures - safety net revenue-to-cost ratio or operating margin.

Instead, we found that several hospital system-level features and state policies were stronger predictors of financial performance. Systems in states with higher Medicaid reimbursement rates and more generous Medicaid eligibility had higher safetynet ratios, as would be expected. Meanwhile, state DSH funding level and state DSH targeting were not significant predictors of financial performance. This finding may be due in part to the sample size reduction (from 98 hospital systems to 62 hospital systems) required to run the analysis on the safety net ratio, since one-third of hospital systems did not report DSH funding in their financial statements. However, it also may simply be a logical reflection of the relative magnitude of total federal and state Medicaid spending 
(about $\$ 415$ billion in 2012 ) versus DSH spending (about $\$ 17$ billion in combined funding in 2012).[21, 22] Overall, one of our key findings is that state policy decisions in particular those that govern Medicaid reimbursement and eligibility - may outweigh demographic characteristics in their ability to shape the financial health of safety-net hospital systems.

In terms of the operating margin, which is a broader measure of hospital performance than looking at just one component of costs and revenues (as in the safetynet ratio), we did not find any significant association with state policy decisions. Two other parameters were the strongest predictors. Hospital systems in the Northeast fared worse on average than systems in the South, West, and Midwest, a finding that may be due in part to financial repercussions from Massachusetts' 2006 health reform, which redirected much of the state's uncompensated care fund away from several large safety net hospitals; [13] however, our findings were persistent even when excluding Massachusetts. Other regional market trends may be to blame, such as high overall levels of health care spending in several Northeastern cities,[23] though we do not have the sample size or variation over time that would be useful to further assess this issue.

Meanwhile, we found that academic medical centers were at a significant advantage compared to other safety net hospital systems in terms of operating margins, even after accounting for state policy decisions and patient case mix. This is consistent with previous research on indirect medical education (IME) funding, which provides academic hospitals with additional funding ostensibly tied to the higher costs of care in teaching facilities. One recent study indicated that current IME levels are two to three 
times as large as what would be an "empirically justified" level.[24, 25] Given that the ACA does not include any IME cuts, university ownership may continue to provide some safety net hospital systems with a financial buffer as Medicaid DSH funds decline substantially over the next five years.

Our paper has several important limitations. First, by virtue of using audited financial statements, which is a time-intensive data source to collect, we were limited to a single year (2010) of pre-ACA financial statements, and our overall sample size was small. The SEC requirement for hospitals to file these financial statements only took effect in 2009, precluding any longer-term historical analyses. In designing our sample, we aimed to target hospital systems that provide the bulk of hospital care in the U.S. health care safety net, by identifying large urban-based systems. However, the fact that we had just a single year and a sample of 98 hospital systems means that our regression analyses may have been underpowered to detect significant associations between financial performance and the demographic, hospital, and policy features we studied. Nonetheless, large effects should have been evident even in this small sample, and we did identify several factors associated with changes in operating margins on the order of 4-6 percentage points, which was roughly the gap between the $1^{\text {st }}$ and $3^{\text {rd }}$ quartiles in our sample.

Our results may not generalize to hospitals involved in safety net care that did not meet our inclusion criteria. More specifically, our observed pattern of predictors of financial performance in large urban safety net hospitals may not apply to rural hospitals 
(including critical access hospitals), small safety net hospitals, and for-profit hospital systems that provide large amounts of care to low-income populations.

Finally, our analysis is by definition a cross-sectional descriptive study. None of the associations identified here can be attributed to a causal relationship without further study and, ideally, policy variation over time. For better or for worse, the ACA is likely to provide just such an experiment for safety net hospitals over the coming decade.

In conclusion, in this exploratory analysis of large urban safety net hospitals, we find that audited financial statements can be used to examine financial performance and identify risk factors for distress. Overall, population demographics appear to play less of a role than state policy decisions such as Medicaid eligibility and payment levels, and hospital governance features - particularly academic affiliation - may be protective for hospitals against the risk of financial distress. Future research will be critical to monitor these patterns over time and identify policy approaches for protecting the hospital safety net in the coming years of immense change. 


\section{REFERENCES}

1. Zaman, O.S., L.C. Cummings, and S. Laycox, America's Safety Net Hospitals and Health Systems, 2010: Results of the Annual NAPH Hospital Characteristics Survey. 2012.

2. Centers for Medicare \& Medicaid Services (CMS), H., Medicaid Program; State Disproportionate Share Hospital Allotment Reductions. Federal Register, 2013. 78(94).

3. Sommers, B.D., et al., Health Reform and Changes in Health Insurance Coverage in 2014. The New England journal of medicine, 2014. 371(9): p. 867-874.

4. Neuhausen, K., M. Spivey, and A.L. Kellermann, State politics and the fate of the safety net. N Engl J Med, 2013. 369(18): p. 1675-7.

5. Millman, J., Doc fix would delay Obamacare Medicaid cuts. That's good news for non-expansion states. 2014, Washington Post.

6. Dorn, S., M. Buettgens, and J. Dev, In States That Don't Expand Medicaid, Who Gets New Coverage Assistance Under the ACA and Who Doesn't? 2014, Urban Institute: Washington, DC.

7. Staff, N., Notice of Proposed Rule Making for DSH Reduction Methodology. 2013: National Association of Medicaid Directors.

8. Bazzoli, G.J., N. Fareed, and T.M. Water, Hospital financial performance in the recent recession and implications for institutions that remain financially weak. Health Affairs, 2014. 33(5): p. 739-745.

9. Kane, N.M. and S.A. Magnus, The Medicare Cost Report and the limits of hospital accountability: improving financial accounting data. Journal Health Politics, Policy and Law, 2001. 26(1): p. 81-105.

10. Kane, N. and N. Turnbull, Safety Net Hospital Financial Performance in 2010. Harvard School of Public Health Working Paper, 2013. (https://cdn1.sph.harvard.edu/wp-content/uploads/sites/496/2012/08/WorkingPaper-on-Safety-Net-Hospital-Financial-Performance-in-2010.pdf).

11. Clark, J., et al., From striving to thriving: systems thinking, strategy, and the performance of safety net hospitals. Health Care Manage Rev, 2013. 38(3): p. 211-23.

12. Cunningham, P.J., G.J. Bazzoli, and A. Katz, Caught in the competitive crossfire: safety-net providers balance margin and mission in a profit-driven health care market. Health Affairs, 2008. 27(5): p. w374-82.

13. Mohan, A., et al., The health of safety net hospitals following Massachusetts health care reform: changes in volume, revenue, costs, and operating margins from 2006 to 2009. Int J Health Serv, 2013. 43(2): p. 321-35.

14. Electronic Municipal Market Access: A Service of the Municipal Securities Rulemaking Board. 2014 May 22, 2014]; Available from: http://emma.msrb.org/

15. American Hospital Directory. 2014 May 22, 2014]; Available from: http://www.ahd.com. 
16. Hospital Form 2552-96 Cost Report Data File. 2010 May 22, 2014]; Available from: http://www.cms.gov/Research-Statistics-Data-and-Systems/Files-forOrder/CostReports/Hospital-1996-form.html

17. Cutler, D. and J. Gruber, Does Public Insurance Crowd Out Private Insurance? The Quarterly Journal of Economics, 1996. 11(1): p. 391-460.

18. Graves, J.A., R. Curtis, and J. Gruber, Balancing coverage affordability and continuity under a basic health program option. The New England journal of medicine, 2011.365(24): p. e44.

19. Kaiser, Where are states today? Medicaid and state-funded coverage eligibility levels for low-income adults. 2009, Kaiser Family Foundation: Washington, D.C.

20. Dewan, S. and K. Sack, A Safety-Net Hospital Falls Into Crisis., in New York Times. 2008.

21. Mitchell, A., Medicaid Disproportionate Share Hospital Payments. 2013, Congressional Research Service: Washington, DC.

22. Federal and State Share of Medicaid. 2012 May 22, 2014]; Available from: http://kff.org/medicaid/state-indicator/federalstate-share-of-spending/.

23. Wennberg, J.E., et al., The Dartmouth Atlas of Health Care. 1996, Chicago, IL: American Hospital Publishing, Inc. .

24. Report to the Congress: Medicare Payment Policy. 2007, Medicare Payment Advisory Commission: Washington, DC.

25. Nguyen, N.X. and S.H. Sheingold, Indirect medical education and disproportionate share adjustments to Medicare inpatient payment rates. Medicare Medicaid Research Review, 2011. 1(4). 
Table 1: Summary Statistics for Hospital Systems in Sample (n=98)

\begin{tabular}{|l|l|}
\hline Variable & Percentage of sample \\
\hline Hospital Ownership & $18 \%$ \\
\hline Non-profit & $28 \%$ \\
\hline District owned & $52 \%$ \\
\hline Other publically-owned & $6 \%$ \\
\hline Hospital Governance & a \\
\hline University & $16 \%$ \\
\hline Elected Board of Directors & $54 \%$ \\
\hline Government-Run & $20 \%$ \\
\hline Self-Nominating Board & $8 \%$ \\
\hline Region & $16 \%$ \\
\hline Northeast & $59 \%$ \\
\hline West & $15 \%$ \\
\hline South & $17 \%$ \\
\hline Midwest & $7 \%$ \\
\hline Hospital Area Demographics & \\
\hline \% Below Federal Poverty Level & $39 \%$ \\
\hline \% Non-Citizens & \\
\hline$\%$ Non-White or Latino or Latino &
\end{tabular}

\section{NOTES}

Source: Authors' analysis of hospital financial statements and data from the American Community Survey. a) 2 hospital systems did not reveal their governance structure. For analytic purposes, the two observations were classified with the reference group (government-run) in the analyses in Tables 2-4.

b) Based on the population demographics of the hospitals' surrounding area, as measured by the Public-Use Microdata Area (PUMA) in the Census Bureau's American Community Survey (ACS). See methods for full details. 


\section{Table 2: Predictors of High-Medicaid Payer Mix Among Safety Net Hospital Systems (n=98)}

\begin{tabular}{|c|c|c|c|c|c|c|}
\hline & \multicolumn{3}{|c|}{ Univariate } & \multicolumn{3}{|c|}{ Multivariate } \\
\hline Variable & Estimate & $95 \% \mathrm{CI}$ & P-value & Estimate & $95 \% \mathrm{CI}$ & $\begin{array}{l}\text { P- } \\
\text { value }\end{array}$ \\
\hline \multicolumn{7}{|l|}{ Hospital Ownership } \\
\hline Non-Profit & 0.25 & $(-0.03,0.53)$ & 0.07 & 0.16 & $(-0.22,0.53)$ & 0.41 \\
\hline Other Publically-Owned & 0.02 & $(-0.19,0.23)$ & 0.86 & 0.11 & $(-0.12,0.35)$ & 0.34 \\
\hline District Owned & Reference & -- & -- & Reference & -- & -- \\
\hline \multicolumn{7}{|l|}{ Hospital Governance } \\
\hline University & 0.08 & $(-0.31,0.48)$ & 0.68 & -0.06 & $(-0.45,0.33)$ & 0.77 \\
\hline $\begin{array}{l}\text { Elected Board of } \\
\text { Directors }\end{array}$ & 0.13 & $(-0.14,0.39)$ & 0.35 & 0.14 & $(-0.10,0.39)$ & 0.25 \\
\hline Self-Nominating Board & 0.15 & $(-0.09,0.39)$ & 0.22 & 0.11 & $(-0.17,0.39)$ & 0.43 \\
\hline Government-Run & Reference & -- & -- & Reference & -- & -- \\
\hline \multicolumn{7}{|c|}{ Hospital Area Demographics } \\
\hline $\begin{array}{l}\text { \% Below Federal } \\
\text { Poverty Level }\end{array}$ & 0.67 & $(-0.57,1.92)$ & 0.30 & 0.14 & $(-1.40,1.67)$ & 0.86 \\
\hline$\%$ Non-Citizens & 2.29 & $(0.94,3.64)$ & 0.001 & 0.69 & $(-1.20,2.58)$ & 0.47 \\
\hline$\%$ Non-White or Latino & 0.67 & $(0.30,1.04)$ & $<0.001$ & 0.48 & $(-0.09,1.06)$ & 0.10 \\
\hline \multicolumn{7}{|l|}{ Region } \\
\hline Northeast & 0.29 & $(-0.10,0.68)$ & 0.14 & -0.33 & $(-0.80,0.15)$ & 0.18 \\
\hline West & 0.20 & $(-0.15,0.49)$ & 0.30 & 0.07 & $(-0.26,0.39)$ & 0.69 \\
\hline South & -0.13 & $(-0.39,0.13)$ & 0.32 & -0.15 & $(-0.78,0.47)$ & 0.62 \\
\hline Midwest & Reference & -- & -- & Reference & -- & -- \\
\hline \multicolumn{7}{|c|}{ State Policies (without Regional Adjustment) } \\
\hline Low DSH State & -0.02 & $(-0.38,0.34)$ & 0.90 & 0.03 & $(-0.37,0.42)$ & 0.89 \\
\hline $\begin{array}{l}\text { DSH Fund Targeting } \\
\text { Index }\end{array}$ & 2.59 & $(-6.12,11.30)$ & 0.56 & -2.60 & $(-13.13,7.92)$ & 0.62 \\
\hline $\begin{array}{l}\text { Medicaid Eligibility } \\
\text { Index }\end{array}$ & 5.59 & $(3.12,8.05)$ & $<0.001$ & 3.94 & $(0.85,7.02)$ & 0.013 \\
\hline $\begin{array}{l}\text { Medicaid Payment-to- } \\
\text { Cost Ratio }\end{array}$ & -0.51 & $(-0.93,-0.10)$ & 0.017 & -0.36 & $(-0.76,0.03)$ & 0.07 \\
\hline
\end{tabular}

\section{NOTES}

Estimates are regression coefficients from a linear probability model analyzing the binary outcome of "High Medicaid-payer mix," defined as hospitals for which at least $25 \%$ of hospitals days are paid for by Medicaid.

Source: Authors' analysis of hospital financial statements and data from the American Community Survey. 
Table 3: Predictors of Safety Net Revenue-to-Cost Ratio, Among Safety Net Hospital Systems (n=62)

\begin{tabular}{|c|c|c|c|c|c|c|}
\hline & \multicolumn{3}{|c|}{ Univariate } & \multicolumn{3}{|c|}{ Multivariate } \\
\hline Variable & Estimate & $95 \% \mathrm{CI}$ & P-value & Estimate & $95 \% \mathrm{CI}$ & P-value \\
\hline \multicolumn{7}{|l|}{ Hospital Ownership } \\
\hline Non-Profit & -0.29 & $(-0.87,0.28)$ & 0.31 & -0.82 & $(-1.55,-0.09)$ & 0.03 \\
\hline Other Publically-Owned & -0.10 & $(-0.55,0.36)$ & 0.67 & -0.40 & $(-0.94,0.13)$ & 0.14 \\
\hline District Owned & Reference & -- & -- & Reference & -- & -- \\
\hline \multicolumn{7}{|l|}{ Hospital Governance } \\
\hline University & -0.46 & $(-1.12,0.19)$ & 0.16 & -0.50 & $(-1.18,0.18)$ & 0.14 \\
\hline $\begin{array}{l}\text { Elected Board of } \\
\text { Directors }\end{array}$ & 0.17 & $(-0.44,0.79)$ & 0.57 & 0.22 & $(-0.34,0.79)$ & 0.43 \\
\hline Self-Nominating Board & -0.18 & $(-0.68,0.31)$ & 0.47 & 0.14 & $(-0.37,0.65)$ & 0.59 \\
\hline $\begin{array}{l}\text { Government-Run or } \\
\text { Other }\end{array}$ & Reference & -- & -- & Reference & -- & -- \\
\hline \multicolumn{7}{|c|}{ Hospital Area Demographics } \\
\hline $\begin{array}{l}\text { \% Below Federal } \\
\text { Poverty Level }\end{array}$ & 1.71 & $(-0.54,3.96)$ & 0.13 & 1.27 & $(-1.81,4.36)$ & 0.41 \\
\hline$\%$ Non-Citizens & 1.43 & $(-1.39,4.24)$ & 0.32 & -2.20 & $(-6.24,1.84)$ & 0.28 \\
\hline$\%$ Non-White or Latino & 0.32 & $(-0.45,1.10)$ & 0.40 & 0.16 & $(-1.03,1.36)$ & 0.79 \\
\hline \multicolumn{7}{|l|}{ Region } \\
\hline Northeast & 0.24 & $(-0.51,0.99)$ & 0.53 & 0.11 & $(-0.77,0.98)$ & 0.80 \\
\hline West & -0.37 & $(-1.12,0.38)$ & 0.33 & -0.24 & $(-0.99,0.52)$ & 0.54 \\
\hline South & -0.23 & $(-0.78,0.32)$ & 0.41 & -0.64 & $(-1.18,-0.09)$ & 0.02 \\
\hline Midwest & Reference & -- & -- & Reference & -- & -- \\
\hline \multicolumn{7}{|c|}{ State Policies (without Regional Adjustment) } \\
\hline Low DSH State & 0.54 & $(-0.53,1.61)$ & 0.32 & 0.58 & $(-0.47,1.64)$ & 0.27 \\
\hline $\begin{array}{l}\text { DSH Fund Targeting } \\
\text { Index }\end{array}$ & -0.40 & $\begin{array}{l}(-18.45 \\
17.64)\end{array}$ & 0.96 & -10.81 & $\begin{array}{l}(-32.06 \\
10.45)\end{array}$ & 0.31 \\
\hline $\begin{array}{l}\text { Medicaid Eligibility } \\
\text { Index }\end{array}$ & 3.97 & $(-0.82,8.76)$ & 0.10 & 8.66 & $(2.34,14.97)$ & 0.008 \\
\hline $\begin{array}{l}\text { Medicaid Payment-to- } \\
\text { Cost Ratio }\end{array}$ & 1.27 & $(0.61,1.93)$ & $<0.001$ & 1.36 & $(0.69,2.02)$ & $<0.001$ \\
\hline
\end{tabular}

\section{NOTES}

Estimates are regression coefficients from a linear model.

Source: Authors' analysis of hospital financial statements and data from the American Community Survey. 
Table 4: Predictors of Operating Margin Among Safety Net Hospital Systems $(\mathbf{n}=98)$

\begin{tabular}{|c|c|c|c|c|c|c|}
\hline & \multicolumn{3}{|c|}{ Univariate } & \multicolumn{3}{|c|}{ Multivariate } \\
\hline Variable & Estimate & $95 \% \mathrm{CI}$ & P-value & Estimate & $95 \%$ CI & $\begin{array}{l}\text { P- } \\
\text { value }\end{array}$ \\
\hline \multicolumn{7}{|l|}{ Hospital Ownership } \\
\hline Non-Profit & -0.01 & $(-0.03,0.02)$ & 0.59 & -0.02 & $(-0.05,0.02)$ & 0.43 \\
\hline Other Publically-Owned & -0.01 & $(-0.03,0.01)$ & 0.52 & -0.01 & $(-0.04,0.01)$ & 0.33 \\
\hline District Owned & Reference & -- & -- & Reference & -- & -- \\
\hline \multicolumn{7}{|l|}{ Hospital Governance } \\
\hline University & 0.04 & $(0.01,0.08)$ & 0.02 & 0.04 & $(0.00,0.08)$ & 0.03 \\
\hline $\begin{array}{l}\text { Elected Board of } \\
\text { Directors }\end{array}$ & 0.01 & $(-0.01,0.04)$ & 0.25 & 0.00 & $(-0.02,0.03)$ & 0.76 \\
\hline Self-Nominating Board & 0.00 & $(-0.02,0.02)$ & 0.85 & 0.01 & $(-0.02,0.04)$ & 0.43 \\
\hline $\begin{array}{l}\text { Government-Run or } \\
\text { Other }\end{array}$ & Reference & -- & -- & Reference & -- & -- \\
\hline \multicolumn{7}{|c|}{ Hospital Area Demographics } \\
\hline $\begin{array}{l}\text { \% Below Federal } \\
\text { Poverty Level }\end{array}$ & -0.04 & $(-0.15,0.08)$ & 0.54 & 0.02 & $(-0.14,0.18)$ & 0.78 \\
\hline$\%$ Non-Citizens & -0.05 & $(-0.18,0.08)$ & 0.45 & -0.03 & $(-0.22,0.16)$ & 0.76 \\
\hline$\%$ Non-White or Latino & 0.00 & $(-0.04,0.03)$ & 0.91 & 0.01 & $(-0.05,0.07)$ & 0.81 \\
\hline \multicolumn{7}{|l|}{ Region } \\
\hline Northeast & -0.05 & $(-0.08,-0.01)$ & 0.006 & -0.06 & $(-0.11,-0.01)$ & 0.016 \\
\hline West & 0.01 & $(-0.02,0.04)$ & 0.41 & 0.00 & $(-0.03,0.04)$ & 0.81 \\
\hline South & -0.01 & $(-0.04,0.01)$ & 0.27 & -0.01 & $(-0.04,0.02)$ & 0.43 \\
\hline Midwest & Reference & -- & -- & Reference & -- & -- \\
\hline \multicolumn{7}{|c|}{ State Policies (without Regional Adjustment) } \\
\hline Low DSH State & 0.03 & $(-0.01,0.06)$ & 0.09 & 0.03 & $(-0.01,0.07)$ & 0.16 \\
\hline $\begin{array}{l}\text { DSH Fund Targeting } \\
\text { Index }\end{array}$ & 0.07 & $(-0.73,0.87)$ & 0.87 & -0.15 & $(-1.25,0.94)$ & 0.78 \\
\hline $\begin{array}{l}\text { Medicaid Eligibility } \\
\text { Index }\end{array}$ & -0.14 & $(-0.38,0.11)$ & 0.27 & -0.08 & $(-0.40,0.24)$ & 0.61 \\
\hline $\begin{array}{l}\text { Medicaid Payment-to- } \\
\text { Cost Ratio }\end{array}$ & 0.00 & $(-0.04,0.04)$ & 0.90 & 0.01 & $(-0.04,0.05)$ & 0.79 \\
\hline
\end{tabular}

\section{NOTES}

Estimates are regression coefficients from a linear model.

Source: Authors' analysis of hospital financial statements and data from the American Community Survey. 
Figure 1: Sample Distribution of Financial Performance Measures, 2010

PANEL A: Safety Net Revenue-to-Cost Ratio Among Safety Net Hospital Systems (n=62)

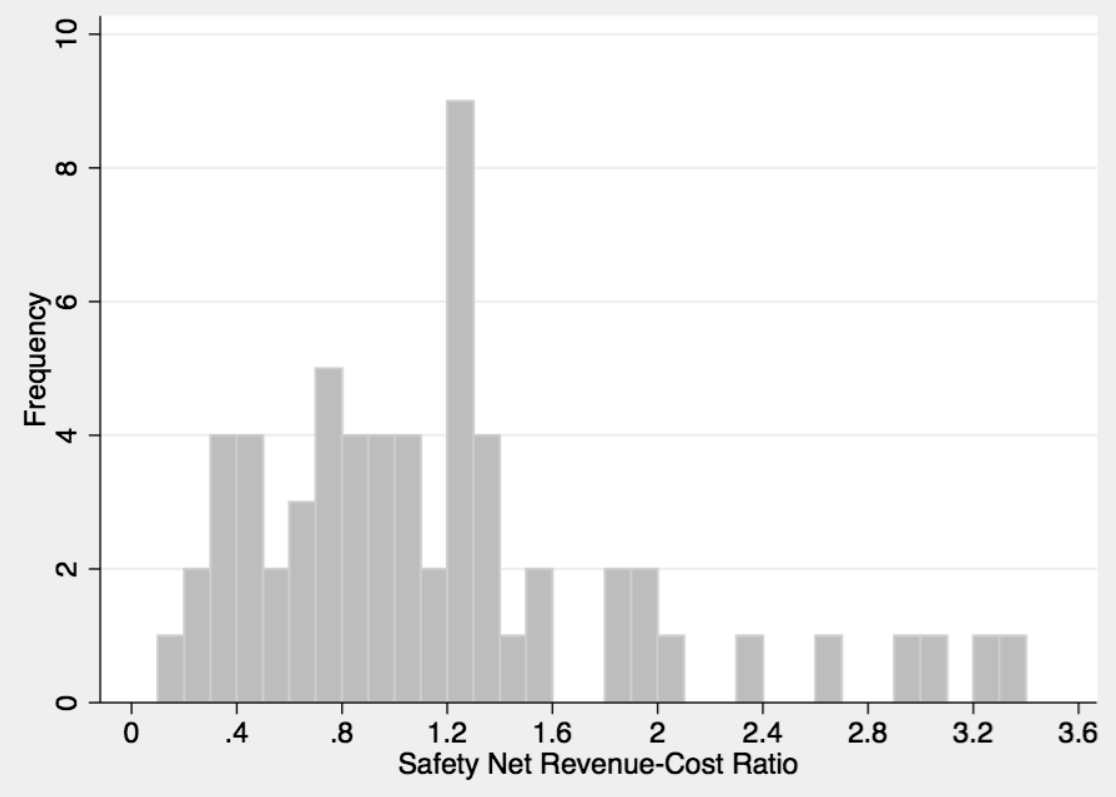

PANEL B: Operating Margin Among Safety Net Hospital Systems (n=98)

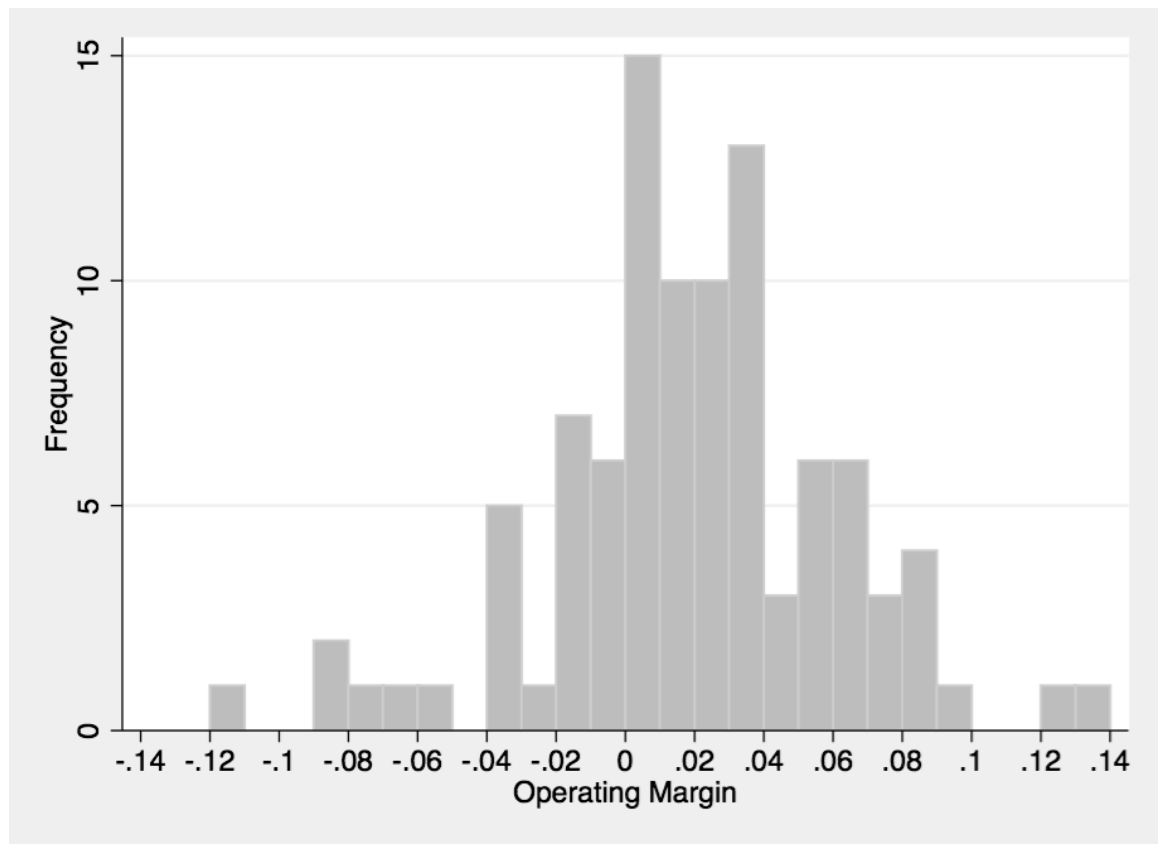

NOTES

Source: Authors' analysis of hospital financial statements. 